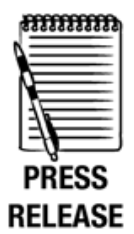

See Editorial, p 742

- Additional material is published online only. To view this file please visit the journal online (http://thorax.bmj.com).

${ }^{1}$ Centre for Environmental Sciences, Hasselt University, Diepenbeek, Belgium

${ }^{2}$ School of Public Health, Lung Toxicology Unit, Katholieke Universiteit Leuven and University Hospital

Gasthuisberg, Leuven, Belgium ${ }^{3}$ Laboratory of Pneumology, Katholieke Universiteit Leuven and University Hospital Gasthuisberg, Leuven, Belgium ${ }^{4}$ Lung Transplantation Unit, Katholieke Universiteit Leuven and University Hospital Gasthuisberg, Leuven, Belgium ${ }^{5}$ Department of Thoracic Surgery, Katholieke Universiteit Leuven and University Hospital Gasthuisberg, Leuven, Belgium ${ }^{6}$ Interuniversity Institute of Biostatistics, Hasselt University, Diepenbeek, Belgium

\section{Correspondence to}

Dr Bart M Vanaudenaerde, Labo Pneumologie, Box 706 ,

Katholieke Universiteit Leuven, 49 Herestraat, B-3000 Leuven, Belgium; bart.vanaudenaerde@ med.kuleuven.be

Received 8 November 2010 Accepted 13 January 2011 Published Online First 23 March 2011

\title{
The impact of traffic air pollution on bronchiolitis obliterans syndrome and mortality after lung transplantation
}

\author{
Tim S Nawrot, ${ }^{1,2}$ Robin Vos, ${ }^{3,4}$ Lotte Jacobs, $^{2}$ Stijn E Verleden, ${ }^{3,4}$ Shana Wauters, ${ }^{4}$ \\ Veerle Mertens, ${ }^{4}$ Christophe Dooms, ${ }^{3}$ Peter H Hoet, ${ }^{2}$ Dirk E Van Raemdonck, ${ }^{4,5}$ \\ Christel Faes, ${ }^{6}$ Lieven J Dupont, ${ }^{3,4}$ Benoit Nemery, ${ }^{2}$ Geert M Verleden, ${ }^{3,4}$ \\ Bart M Vanaudenaerde ${ }^{3,4}$
}

\begin{abstract}
Background Approximately half of all patients who underwent a lung transplantation suffer from bronchiolitis obliterans syndrome (BOS), the clinical correlate of chronic rejection, within 5 years after transplantation. This prevalence is much higher than for other solid organ transplantations, possibly due to the lung's direct contact with the environment. The authors assessed the association between proximity of the home to major roads and BOS and mortality in a cohort of patients after lung transplantation.
\end{abstract}

Methods The authors calculated hazard ratios for BOS and mortality in relation to proximity of the home to major roads, adjusting for relevant covariables, in 288 patients after lung transplantation at the Leuven University Hospital between 1997 and 2009 and with follow-up until August 2009. Inflammatory parameters in plasma and bronchoalveolar lavage were assessed in 207 patients.

Results During follow-up, 117 (41\%) patients developed BOS and $61(21 \%)$ died. Patients who lived within $171 \mathrm{~m}$ of a major road (lowest tertile) were 2.06 (95\% Cl 1.39 to 3.05) times more likely to develop BOS and 2.20 (1.25 to 3.86) times more likely to die than patients living farther away. The adjusted hazard ratios of BOS and mortality were 0.57 and 0.72 for each 10 -fold increase in distance from major roads. Proximity to a major road was inversely associated with plasma C-reactive protein levels, neutrophil percentage and interleukin-6 concentration in bronchoalveolar lavage.

Conclusion Traffic-related air pollution appears to constitute a serious risk of BOS and mortality after lung transplantation.

\section{INTRODUCTION}

Lung transplantation is an accepted treatment option for patients with end-stage lung disease. The long-term survival of patients after lung transplantation (median of 5 years) is much lower than for other solid organ transplantation. ${ }^{1}$ This is mainly because half the patients develop bronchiolitis obliterans syndrome (BOS) - the clinical correlate of chronic rejection-within 5 years of transplantation. BOS is the most important cause of late mortality $(25-35 \%)^{2}$

BOS is triggered by alloimmune and non-alloimmune risk factors, such as HLA mismatch, acute rejection, receptor/donor age, cytomegalovirus (CMV) and other viral infections. ${ }^{2}$ Recently, airway colonisation by Pseudomonas, lymphocytic bronchitis/ bronchiolitis and gastro-oesophageal reflux have been added as risk factors. ${ }^{3-7}$ These risk factors act via neutrophilic airway inflammation, suggesting that activation of the innate immune system is a trigger of BOS. Many inhaled air pollutants also give rise to activation of the innate immune system. ${ }^{89}$ Moreover, air pollution exposure exerts adverse health effects, especially in patients with cardiopulmonary diseases, ${ }^{10-12}$ and can aggravate chronic inflammatory lung disorders. ${ }^{13}{ }^{14} \mathrm{~A}$ substantial proportion of ambient air pollution results from the combustion of fossil fuels by vehicle traffic. ${ }^{15}$

As the lung is in direct contact with the environment, the authors hypothesised that air pollution may be a risk factor for BOS and mortality after lung transplantation. The incidence of BOS and mortality was assessed in a large cohort of well characterised and closely monitored patients after lung transplantation in relation to their exposure to (traffic-related) air pollution, as measured by the proximity of their home to a major road.

\section{METHODS}

\section{Study design}

This study considered patients who had had a lung transplant between 1 January 1997 and 31 December 2008 with long-term follow-up at UZ Leuven. Of these 403 transplantations, the authors excluded 22 patients living outside Belgium, 24 patients who died within 3 months after transplantation, 29 patients in whom BOS could not be diagnosed according to international criteria (suture stenosis $n=15$, cancer $n=6$, post-transplant lymphoproliferative disease $n=3$, neurological problems $n=1$, pneumonectomy $\mathrm{n}=1$, insufficient follow-up data $\mathrm{n}=3$ ) and 40 patients of the active group in a randomised placebo-controlled trial with azithromycin (inclusion from July 2005 to November 2007). ${ }^{16}$ These 40 patients were excluded because azithromycin was started 1 month after transplantation and reduced neutrophilia and C-reactive protein (CRP), and so abolished the effect of pollution. In seven patients the first and second transplantation were included as two separate transplantations. The study therefore examined 288 lung transplantations in 281 patients whose characteristics are summarised in table 1 . The authors gathered information on gender, donor/receptor age at transplantation, place of residence, socioeconomic status (SES), lifestyle, 
smoking habits, reason for transplantation, type of transplantation, CMV mismatch, primary graft dysfunction, and baseline therapy at about 90 days after transplantation. We coded SES according to the UK Office of Population Censuses and Surveys (1980) and scored it using a scale ranging from 1 to 3. ${ }^{17}$ Smoking habits (not in all patients) were assessed by questionnaire, urinary cotinine and exhaled carbon monoxide. ${ }^{18}$ Relevant clinical information was collected up to 31 August 2009, including BOS and death (main outcomes); bronchoscopic procedures with transbronchial biopsies and bronchoalveolar lavage (BAL); incidences of histopathologically diagnosed acute rejections; treated $\mathrm{CMV}$ infections and treated non-CMV infections; Pseudomonas aeruginosa airway colonisation; gastrooesophageal reflux (gastroscopy or $\mathrm{pH}$ impedance measurement). The Ethical Review Board of the Leuven University Medical Faculty approved the study. All participants gave informed consent at recruitment.

\section{BOS diagnosis, BOS therapy and airway or systemic inflammation}

BOS was detected and diagnosed according to guidelines of the International Society for Heart and Lung Transplantation. ${ }^{19}$ BOS was detected by routine lung function testing. BOS was defined as the occurrence of a sustained ( 3 weeks or more) decrease in forced expiratory volume in the first second $\left(\mathrm{FEV}_{1}\right)$ by at least $20 \%$ from the patient's mean of the two best postoperative $\mathrm{FEV}_{1}$ measurements taken at least 3 weeks apart, in the absence of other causes, which were generally established by bronchoscopy.

All patients received conventional postoperative immunosuppressive and prophylactic treatment, consisting of triple-drug immunosuppressive therapy with methylprednisolone, cyclosporine A or tacrolimus, and azathioprine or mycophenolate mofetil. If BOS was diagnosed, doses were increased or alternative immunosuppressive agents (tacrolimus or mycophenolate mofetil) were given. Total lymph node irradiation or retransplantation was needed in rare instances. From 2002, BOS was treated with azithromycin $(250 \mathrm{mg}$ /day for 5 days followed by $250 \mathrm{mg}$ every other day). Other complications, such as acute rejection, infections and gastro-oesophageal reflux disease, were treated according to the International Society for Heart and Lung Transplantation guidelines and our local experience, as previously described. $^{4}$

Since 2001, routine follow-up after lung transplantation included clinical examination, biochemical, radiological, lung

Table 1 Characteristics of 288 lung transplantations

\begin{tabular}{|c|c|c|c|}
\hline & $\begin{array}{l}\text { Close to a major road } \\
(\leq 171 \mathrm{~m}, \mathrm{n}=96)^{*}\end{array}$ & $\begin{array}{l}\text { Farther away from a major } \\
\text { road }(>171 \mathrm{~m}, \mathrm{n}=192)^{*}\end{array}$ & p-Value \\
\hline Number of BOS events, $\mathrm{n}(\%)$ & $49(51 \%)$ & $69(35 \%)$ & 0.01 \\
\hline Number of deaths, $n(\%)$ & $27(28 \%)$ & $34(18 \%)$ & 0.04 \\
\hline Age at transplantation (years) & $47.5 \pm 14.3$ & $46.3 \pm 13.9$ & 0.49 \\
\hline Mean date of transplantation (SD of year) & $14 / 08 / 2004 \pm 3.2$ & $20 / 03 / 2004 \pm 3.0$ & 0.30 \\
\hline Donor age (years) $\dagger$ & $40.0 \pm 14.5$ & $38.4 \pm 13.1$ & 0.32 \\
\hline Women, n (\%) & $51(53 \%)$ & $78(41 \%)$ & 0.04 \\
\hline Underlying disease, $\mathrm{n}(\%)$ & & & 0.04 \\
\hline Emphysema (COPD) & 47 (49\%) & $77(40 \%)$ & \\
\hline Pulmonary fibrosis & $14(15 \%)$ & $35(18 \%)$ & \\
\hline Cystic fibrosis & $6(6 \%)$ & $38(20 \%)$ & \\
\hline$\alpha 1$-Antitrypsin deficiency & $6(6 \%)$ & $10(5 \%)$ & \\
\hline Pulmonary arterial hypertension & $8(8 \%)$ & $9(5 \%)$ & \\
\hline Others & $15(16 \%)$ & $23(12 \%)$ & \\
\hline Double lung transplantation, $\mathrm{n}(\%)$ & 74 (77\%) & $143(74 \%)$ & 0.63 \\
\hline Ischaemic time (min) & $338 \pm 109$ & $357 \pm 100$ & 0.16 \\
\hline Acute rejections during follow-up & & & 0.75 \\
\hline None & $55(57 \%)$ & $101(52 \%)$ & \\
\hline Once & $27(28 \%)$ & $59(31 \%)$ & \\
\hline Twice or more & $14(15 \%)$ & $32(17 \%)$ & \\
\hline CMV infection $\geq 1, n(\%)$ & $17(18 \%)$ & $24(13 \%)$ & 0.23 \\
\hline Other infections & & & 0.81 \\
\hline None & $49(51 \%)$ & $97(51 \%)$ & \\
\hline Once & $24(25 \%)$ & $54(28 \%)$ & \\
\hline Twice of more & $23(24 \%)$ & $41(21 \%)$ & \\
\hline Pseudomonas colonisation & $32(33 \%)$ & $67(35 \%)$ & 0.77 \\
\hline Gastro-oesophageal reflux $\dagger$ & $42(33 \%)$ & $86(67 \%)$ & 0.93 \\
\hline Smokers before transplantation, $\neq \mathrm{n}(\%)$ & $35(64 \%)$ & $66(56 \%)$ & 0.37 \\
\hline Smokers after transplantation, $\neq \mathrm{n}(\%)$ & $8(14 \%)$ & $12(9 \%)$ & 0.33 \\
\hline Socioeconomic status & & & 0.72 \\
\hline Low & $55(57 \%)$ & $106(55 \%)$ & \\
\hline Middle & $33(34 \%)$ & $64(33 \%)$ & \\
\hline High & $8(8 \%)$ & $22(11 \%)$ & \\
\hline Interpolated $\mathrm{PM}_{10}, \mu \mathrm{g} / \mathrm{m}^{3}$ & $31.2 \pm 4.8$ & $29.6 \pm 5.1$ & 0.01 \\
\hline Interpolated $\mathrm{NO}_{2}, \mu \mathrm{g} / \mathrm{m}^{3}$ & $26.8 \pm 7.6$ & $25.7 \pm 7.7$ & 0.24 \\
\hline
\end{tabular}


functional and bronchoscopic examinations at fixed time points $(3,9,12,18,24$ and 36 months post transplant). These procedures were repeated whenever complications were suspected. Bronchoscopy always included BAL for microbiological assessment, quantification of cell differentials, and protein levels (interleukin-6 (IL-6), IL-8); transbronchial biopsies were routinely taken at 90 days post transplant and when indicated. ${ }^{4} 20$

\section{Exposure measurements}

To characterise exposure to traffic-related air pollution, a residence-based approach was adopted, as previously described. ${ }^{21}$ Home addresses at baseline were geocoded with a geographic information system. Using official digitised maps, distances between homes and major roads (defined as 1, 2 or 3-highways, national roads or large local roads respectively) were calculated with a precision of at least $5 \mathrm{~m} .{ }^{21}$ The minimal proximity to a major road was set at $10 \mathrm{~m}$. An indicator variable was constructed for street canyons.

To assess background air pollution, daily mean values were calculated for particulate matter with a diameter less than $10 \mu \mathrm{m}\left(\mathrm{PM}_{10}\right)$ and $\mathrm{NO}_{2}$ for the year 2002 (midpoint of the baseline examination, as done by Miller et al ${ }^{12}$ at each participant's home address, using a validated model $^{22}$ that provides interpolated values for $\mathrm{PM}_{10}$ and $\mathrm{NO}_{2}$ in 4 by $4 \mathrm{~km}$ grids based on the Belgian telemetric air quality network. The interpolation is based on a detrended Kriging interpolation method using landcover data obtained from satellite images (Corine landcover dataset). The model has shown a good agreement between the daily model-derived values and the measured air pollution. ${ }^{22}$ Besides using 2002 as the reference year, sensitivity analysis was also performed for 2000 and the mean of 2000-2006.

\section{Statistical methods}

For database management and statistical analyses, SAS software version 9.1 was used. Means were compared using the standardised normal $z$ test, medians using the Mann-Whitney test, and proportions using the $\chi^{2}$ test. Log-transformed variables were described by their geometric mean and the 5 th-95th percentiles. All statistical tests were two sided.

Survival or incidence curves were constructed by Kaplan-Meier survival function estimates and the log-rank test. Cox regression was applied to model the relation between failure

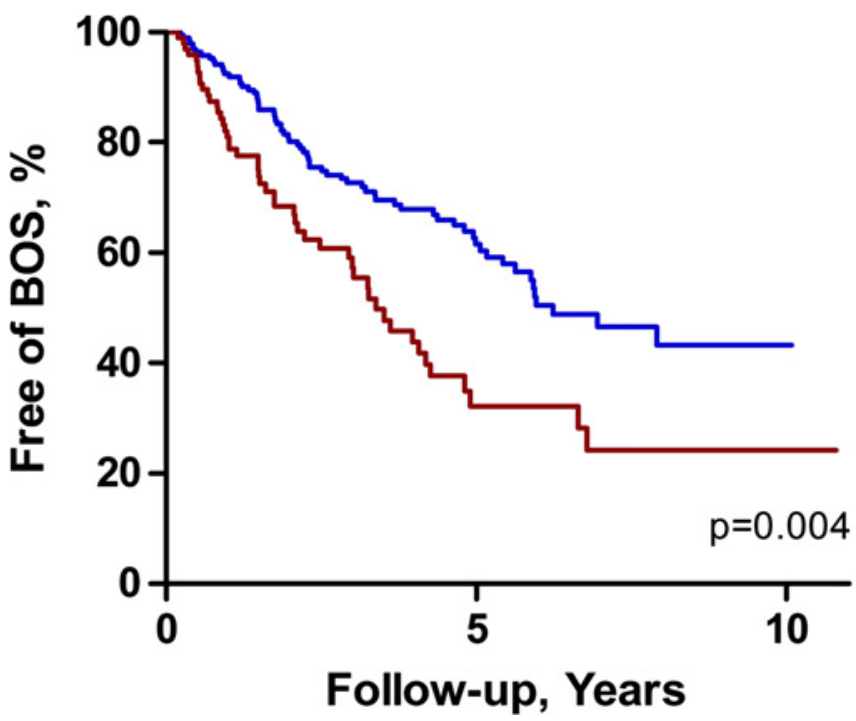

time (ie, occurrence of BOS or death) and distance from major roads, with and without adjusting for other potential explanatory variables including sex, age, SES, type of transplantation (single or double lung transplantation), cumulative rates of CMV and non-CMV infections, cumulative rates of acute rejection, and year of transplantation. Distance from major roads was log-transformed because this parameter had a skewed distribution and also because traffic-related pollutants decay exponentially with increasing distance from roads. ${ }^{23}$ Nonproportionality was tested by the Kolmogorov-type supremum test, as implemented in the PROC PHREG procedure of the SAS package, and by testing the interaction terms between follow-up duration and the log of distance to major roads. For the model of both BOS and death the result of the Kolmogorov-type supremum test was not significant for log distance (all p>0.21). Therefore, the 'proportional hazards assumption' was not violated. The study also investigated associations using a cut-off point of $171 \mathrm{~m}$, based on the lowest tertile of distances between home and the nearest major road. The shape of the association was studied by using fractional polynomials (see online supplement). Based on the best model, the hazard ratio (HR) was calculated with $1000 \mathrm{~m}$ as reference.

Attributable and population-attributable fractions were calculated using standard formulas to estimate the number of events of BOS or deaths that would not have occurred at defined distances from major roads. ${ }^{24}$ Finally, while adjusting for time after transplantation, we regressed inflammatory parameters (cell count, neutrophilia, IL-6, and IL-8 in BAL and plasma CRP) and distance to major roads at different time points after transplantation, using mixed models to account for intra-individual variation.

\section{RESULTS}

The studied cohort included 288 lung transplantations (in 281 patients) and accrued 939 person-years, with a median follow-up of 2.7 years (range 0.2-10.8) from January 1997 to August 2009. During this period, there were 117 (41\%) events of BOS and 61 (21\%) patients died. The characteristics of the 96 patients who had had a lung transplant (lowest tertile) and lived close (within $171 \mathrm{~m})$ to a major road did not differ from those $(\mathrm{n}=192)$ who lived further than $171 \mathrm{~m}$ (table 1).

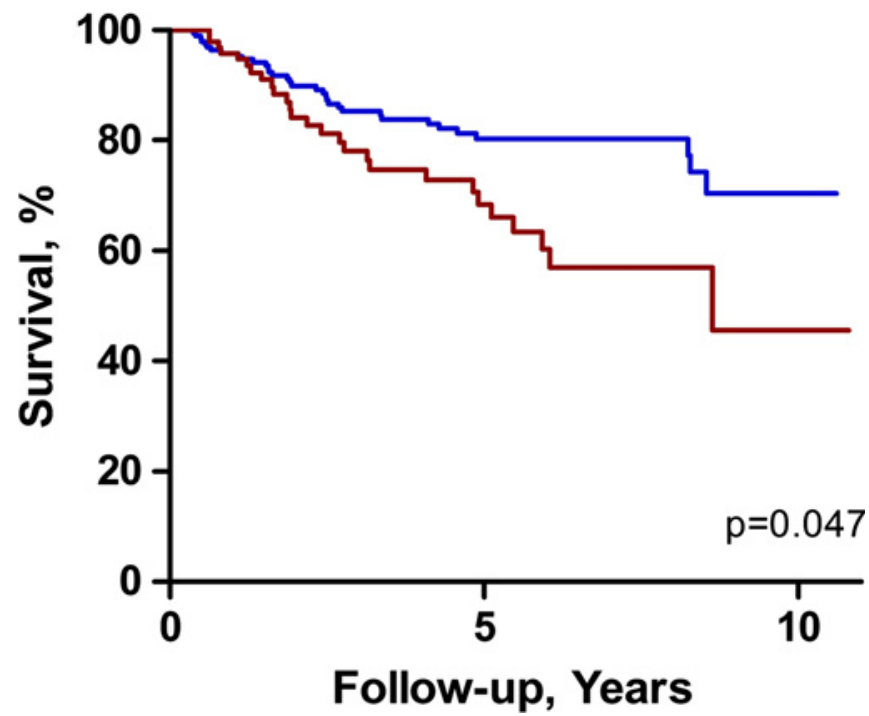

Figure 1 Unadjusted Cox regression in patients after lung transplantation classified according to whether they lived within $171 \mathrm{~m}$ of a major road ( $n=96$, lowest tertile, red line) or more than $171 \mathrm{~m}$ from a major road ( $n=192$, blue line). B0S, bronchiolitis obliterans syndrome. 
The crude rate of BOS was higher $(\mathrm{p}<0.001)$ in patients living close $(\leq 171 \mathrm{~m})$ to major roads (19.3 per 100 person-years) compared with those living farther away (9.9 per 100 personyears; figure 1). The corresponding figures for mortality during follow-up were 7.6 per 100 person-years in patients living close to major roads and 3.9 deaths per 100 person-years in those living more than $171 \mathrm{~m}$ away $(\mathrm{p}<0.001$; figure 1$)$.

The risk of BOS was not associated with gender $(p=0.49)$, age $(p=0.26)$ or non-CMV infections $(p=0.59)$. However, recipients of double lung transplantations had a lower risk (HR 0.56, 95\% CI 0.35 to $0.92, p=0.021$ ) of developing BOS. BOS was also associated with the number of acute rejections (HR 1.77, 95\% CI 1.33 to $2.36, p<0.001$ if more than two acute rejections compared with none) and with CMV infection during follow-up (HR $1.45,95 \%$ CI 0.90 to $2.36, p=0.13$ compared with no CMV infection), and was lower in those with a higher SES (HR 0.31, $95 \%$ CI 0.12 to $0.77, \mathrm{p}=0.01$ ).

The risk of death was not associated with gender $(p=0.17)$, age $(p=0.32)$ or type of transplantation $(p=0.11)$. However, mortality was associated with the number of acute rejections (HR 2.35, 95\% CI 1.59 to 3.46, $\mathrm{p}<0.0001$ if more than two acute rejections compared with none), with CMV infections (HR 1.83, $95 \%$ CI 0.99 to $3.38, p=0.05$ compared with no infections), and with non-CMV infection (HR 2.78, 95\% CI 1.44 to 5.36, $\mathrm{p}=0.002$ if more than two infections compared with none).

Patients with BOS during follow-up had a near twofold increased risk of dying (HR 2.05, 95\% CI 1.21 to 3.46, $\mathrm{p}=0.008$ ) compared with those who were BOS free. Patients receiving azithromycin for BOS had a 46\% lower risk of dying (HR 0.24, $95 \%$ CI 0.12 to $0.50, \mathrm{p}<0.0001)$.

The risks of BOS and death increased with proximity to major roads. In unadjusted analyses, living within $171 \mathrm{~m}$ of a major road was associated with HRs of 2.06 (95\% CI 1.39 to 3.05) for developing BOS and 2.20 (95\% CI 1.25 to 3.86) for dying compared with living farther away (table 2), yielding population attributable fractions of $25 \%$ and $28 \%$ respectively. These HRs increased after adjustment for gender, age, single or double lung transplantation, acute rejection rate, CMV or non-CMV infection rates, SES, and additional adjustments for the average background levels of $\mathrm{PM}_{10}$ in the area of residence (table 2). Figure 2 provides the $\mathrm{HRs}$ and attributable fractions for distances from $50 \mathrm{~m}$ to $800 \mathrm{~m}$ (compared with $1000 \mathrm{~m}$ or more) for $\mathrm{BOS}$ and mortality. The estimated local $\mathrm{PM}_{10}$ background level was not significantly associated with either BOS or death: a $10 \mu \mathrm{g} / \mathrm{m}^{3}$ increase in average background $\mathrm{PM}_{10}$ level gave HRs of 1.15 (95\% CI 0.79 to $1.66, \mathrm{p}=0.47)$ for $\mathrm{BOS}$ and $0.79(95 \% \mathrm{CI}$ 0.43 to $1.42, \mathrm{p}=0.43$ ) for mortality.

After correction for having developed BOS during follow-up and macrolide treatment, the risk of dying after lung transplantation decreased by $31 \%$ (HR $0.69,95 \%$ CI 0.43 to 1.12 , $\mathrm{p}=0.14$ ) for each 10 -fold increase in distance between home and a major road.

A subanalysis of the cohort with reliable data on smoking status (172 patients; $70 \%$ of the total population) demonstrated similar results as in the entire group (see online supplement).

In further sensitivity analyses, the authors evaluated a potential interaction between major road distance and an indicator variable for residence in street canyons $(n=12)$, but this interaction was not significant ( $p$ for interaction=0.93). Models in which the interpolated $\mathrm{PM}_{10}$ (table 2 ) was replaced by interpolated $\mathrm{NO}_{2}$ did not alter the reported associations.

In 207 lung transplant patients, followed from day 50 until 3.5 years after transplantation, there were 943 BALs and 929 plasma samples.

For analysing inflammatory parameters with respect to distance (log), multivariate linear mixed-effect models were used to take the clustering pattern into account (table 3). The proportions of BAL neutrophils, BAL IL- 6 and plasma CRP were inversely associated with distance of the home to the nearest major road (table 3).

For all previous reported analyses, the sensitivity analyses, in which seven retransplantations were excluded, confirmed the study's findings.

\section{DISCUSSION}

Traffic-related air pollution, as estimated by the proximity of the home to a major road, is a major risk factor for BOS and mortality after lung transplantation. The risk was present in either a dichotomous or a continuous analysis, and was not affected by adjustments for relevant covariables. Indicators of pulmonary (BAL neutrophils, IL-6) and systemic (plasma CRP) inflammation, which are probably involved in the onset of BOS, were also associated with proximity to traffic.

The strengths of our study include the relatively large lung transplant population from a single centre and the statistically

Table 2 Proximity of residence to a major road as predictor of bronchiolitis obliterans syndrome (BOS) and mortality

\begin{tabular}{|c|c|c|c|c|c|c|}
\hline \multirow[b]{2}{*}{ Model } & \multicolumn{3}{|c|}{$\begin{array}{l}\text { Proximity to a major road } \leq 171 \\
\text { vs }>171 \mathrm{~m}^{*}\end{array}$} & \multicolumn{3}{|c|}{ Each 10 -fold increase in distance $\dagger$} \\
\hline & $\overline{\text { HR }}$ & $95 \% \mathrm{Cl}$ & $\overline{p \text {-Value }}$ & HR & $95 \% \mathrm{CI}$ & p-Value \\
\hline \multicolumn{7}{|l|}{ Incidence of BOS } \\
\hline Unadjusted & 2.06 & 1.39 to 3.05 & $<0.001$ & 0.62 & 0.47 to 0.85 & 0.004 \\
\hline Adjusted for multiple covariates & 2.15 & 1.44 to 3.22 & $<0.001$ & 0.57 & 0.44 to 0.81 & $<0.001$ \\
\hline $\begin{array}{l}\text { Adjusted for multiple covariates } \ddagger \text { and } \\
\mathrm{PM}_{10} \text { background levels } \S\end{array}$ & 2.18 & 1.44 to 3.01 & $<0.001$ & 0.58 & 0.43 to 0.81 & 0.001 \\
\hline \multicolumn{7}{|l|}{ Incidence of mortality } \\
\hline Unadjusted & 2.20 & 1.25 to 3.86 & 0.006 & 0.63 & 0.40 to 0.99 & 0.047 \\
\hline Adjusted for multiple covariates $\ddagger$ & 1.99 & 1.09 to 3.61 & 0.024 & 0.72 & 0.45 to 0.96 & 0.034 \\
\hline $\begin{array}{l}\text { Adjusted for multiple covariates } \ddagger \text { and } \\
\mathrm{PM}_{10} \text { background levels } \S\end{array}$ & 2.26 & 1.20 to 4.27 & 0.012 & 0.58 & 0.36 to 0.93 & 0.024 \\
\hline
\end{tabular}

*Patients were assigned to categories according to distance from home to major roads based on lowest tertile.

†Continuous analysis based on log-distance; hazard ratio (HR) associated with a 10 -fold increase in distance between home and a major road.

¥Adjusted for sex, age, type of transplantation (single or double lung transplantation), infection with cytomegalovirus (CMV) and non-CMV infections, acute rejections, socioeconomic status, and a time factor to adjust for possible time trends.

$\S$ Background levels of particulate matter with a diameter less than $10 \mu \mathrm{m}\left(\mathrm{PM}_{10}\right)$ at home based on interpolated data $(4$ by $4 \mathrm{~km}$ grids). 


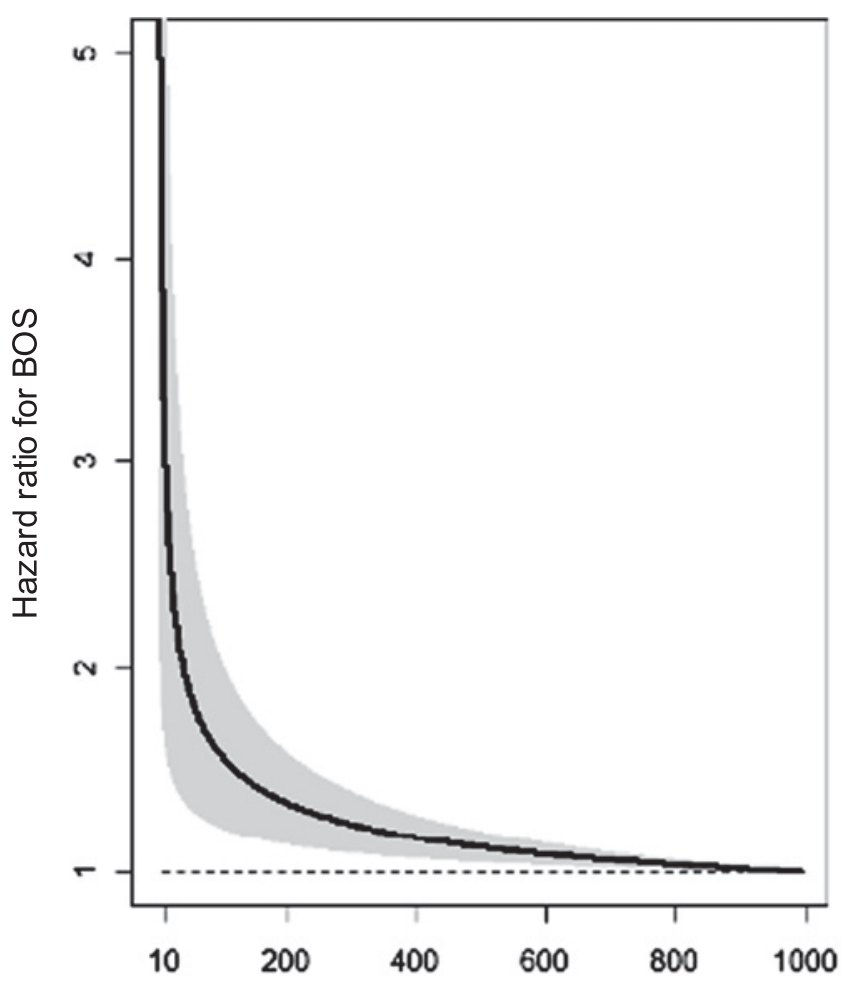

Residential distance to major road (m)

\begin{tabular}{ccc}
$\begin{array}{c}\text { Distance to } \\
\text { major road, } \mathbf{m}\end{array}$ & $\begin{array}{c}\text { Hazard ratio } \\
(\mathbf{9 5 \%} \text { Cl) for BOS }\end{array}$ & $\begin{array}{c}\text { Attributable } \\
\text { fraction }\end{array}$ \\
\hline \hline $\mathbf{1 0 0 0}$ & 1.00 & - \\
$\mathbf{8 0 0}$ & $1.04(1.02-1.06)$ & $3.8 \%$ \\
$\mathbf{6 0 0}$ & $1.09(1.04-1.14)$ & $8.2 \%$ \\
$\mathbf{4 0 0}$ & $1.17(1.04-1.28)$ & $14.7 \%$ \\
$\mathbf{2 0 0}$ & $1.34(1.14-1.58)$ & $25.4 \%$ \\
$\mathbf{1 5 0}$ & $1.43(1.17-1.74)$ & $30.0 \%$ \\
$\mathbf{1 0 0}$ & $1.57(1.22-2.02)$ & $36.3 \%$ \\
$\mathbf{5 0}$ & $1.88(1.32-2.66)$ & $46.7 \%$
\end{tabular}

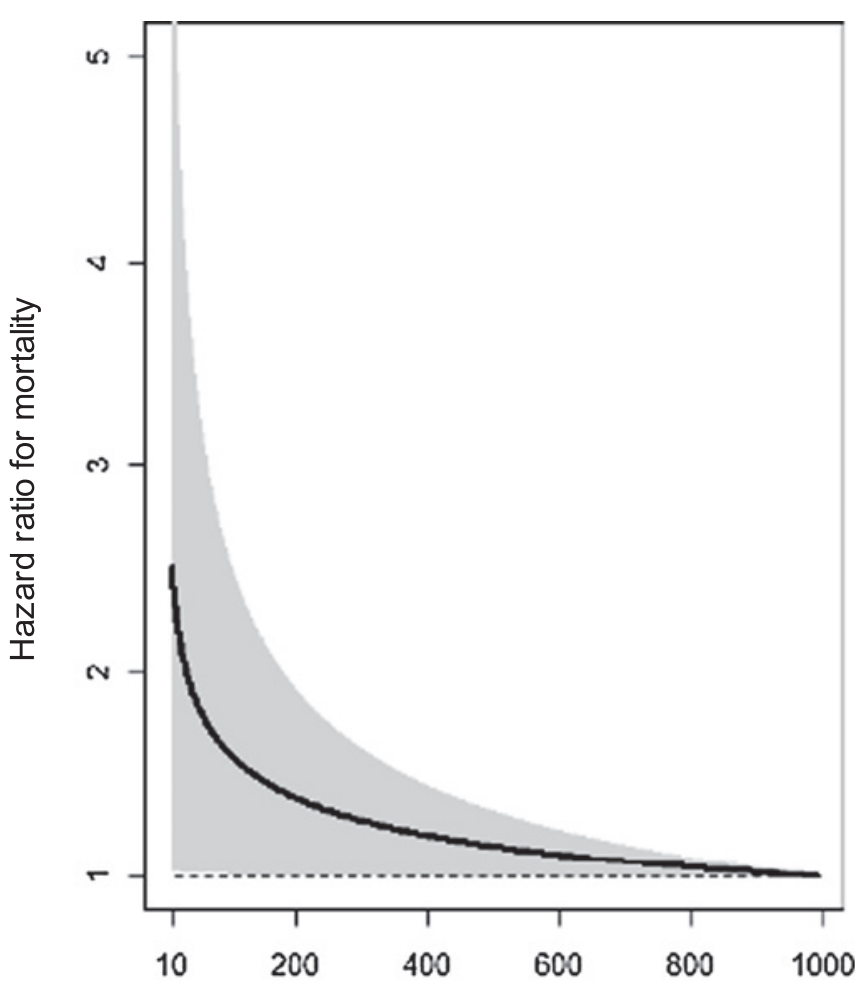

Residential distance to major road (m)

\begin{tabular}{ccc}
$\begin{array}{c}\text { Distance to } \\
\text { major road, } \mathbf{m}\end{array}$ & $\begin{array}{c}\text { Hazard ratio } \\
(\mathbf{9 5 \%} \text { Cl) for mortality }\end{array}$ & $\begin{array}{c}\text { Attrib utable } \\
\text { fraction }\end{array}$ \\
\hline \hline $\mathbf{1 0 0 0}$ & 1.00 & - \\
$\mathbf{8 0 0}$ & $1.05(1.00-1.09)$ & $4.8 \%$ \\
$\mathbf{6 0 0}$ & $1.11(1.00-1.23)$ & $9.8 \%$ \\
$\mathbf{4 0 0}$ & $1.20(1.00-1.45)$ & $16.9 \%$ \\
$\mathbf{2 0 0}$ & $1.39(1.01-1.90)$ & $27.8 \%$ \\
$\mathbf{1 5 0}$ & $1.47(1.01-2.14)$ & $31.9 \%$ \\
$\mathbf{1 0 0}$ & $1.60(1.02-2.52)$ & $37.2 \%$ \\
$\mathbf{5 0}$ & $1.83(1.02-3.30)$ & $45.4 \%$
\end{tabular}

Figure 2 Adjusted hazard ratio (with $95 \% \mathrm{Cl}$, the grey area) for the incidence of bronchiolitis obliterans syndrome (BOS) and mortality in patients after lung transplantation, with $1000 \mathrm{~m}$ as reference. Hazard ratios were adjusted for sex, age, type of transplantation (single or double lung transplantation), infection with cytomegalovirus (CMV) and non-CMV infections, acute rejections, a factor reflecting time trend and social economic status. A corresponding table is given with $\mathrm{HRs}(95 \% \mathrm{Cl})$ and the attributable fractions for the given distances.

robust associations. The statistical significance of our observations follows in part from the high incidence of BOS and mortality. The robustness of the associations is apparent from the fact that inclusion of relevant potential confounders, ranging from SES, transplantation-related characteristics to active smoking, tended to increase the risk estimates. ${ }^{18}$

Many other authors have estimated exposure to traffic-related air pollution by using the geocoded distance between the home and the nearest major road. ${ }^{25-28}$ However, true exposure may differ from the estimated exposure. First, this method does not consider time spent elsewhere than at home, but this limitation may be less relevant in the case of our patient group who presumably were more housebound than other groups. Second, specific traffic counts or diesel-powered vehicle counts were not available. A major road was defined based on an independent, official classification of roads as highways or major local roads, which generally have the heaviest through traffic. It is more likely that some major roads actually had little traffic and that minor roads had a lot of traffic. Therefore the authors believe the (unavoidable) imprecision of the exposure variable probably tended to reduce associations towards the null, rather than to exaggerate them. Finally, only proximity to the nearest major road was evaluated and not the effect of living close to multiple roads (eg, near road junctions), but only a few patients had more than one major road within $200 \mathrm{~m}$ of their home.

In view of the epidemiological evidence about the cardiopulmonary effects of particulate air pollution, ${ }^{26} 27^{29}$ the lack of effect of $\mathrm{PM}_{10}$ was unexpected. However, traffic-related air pollution by ultrafine particles is probably not well captured by (modelled or actual) levels of $\mathrm{PM}_{10}$ or $\mathrm{NO}_{2}$, which are dominated by large-scale geographical and weather-dependent factors. Moreover, Belgium is a small country (approximately 
Table 3 Estimates of lung and systemic inflammation in association with proximity of home to major roads

\begin{tabular}{|c|c|c|}
\hline Change in inflammatory markers & Estimate (95\% CI) & p-Value \\
\hline \multicolumn{3}{|c|}{ Lung inflammation (bronchoalveolar lavage) } \\
\hline Total cell count $\left(\times 10^{6} / \mathrm{ml}\right)$ & $-0.035(-0.1091$ to 0.0386$)$ & 0.350 \\
\hline eutrophils (\%) & $-0.119(-0.2264$ to -0.0112$)$ & 0.031 \\
\hline nterleukin-6 (pg/ml) & $-0.164(-0.3376$ to 0.0092$)$ & 0.064 \\
\hline Interleukin-8 (pg/ml) & $-0.065(-0.1702$ to 0.0409$)$ & 0.230 \\
\hline \multicolumn{3}{|l|}{ Systemic inflammation (plasma) } \\
\hline C-reactive protein (mg/litre) & $-0.107(-0.1935$ to -0.0197$)$ & 0.017 \\
\hline \multicolumn{3}{|c|}{$\begin{array}{l}\text { Estimates express change }(95 \% \mathrm{Cl}) \text { in the dependent variable for a } 10 \text {-fold increase in } \\
\text { distance between home and a major road. The analysis included } 943 \text { observations in } 207 \\
\text { patients; median number of measurements per patient is five (5th-95th percentile: } 1-8) \text {. } \\
\text { Differences based on mixed model, adjusted for clustering and other covariates, as in } \\
\text { previous models, including sex, age, type of transplantation (single or double lung } \\
\text { transplantation), infection with cytomegalovirus (CMV) and non-CMV infections, acute } \\
\text { rejections, a factor reflecting time trend and social economic status. Interaction term } \\
\text { between time after transplantation and distance to a major road was not significant for any } \\
\text { of the studied markers ( } \mathrm{p} \geq 0.52 \text { ). }\end{array}$} \\
\hline
\end{tabular}

$33000 \mathrm{~km}^{2}$ ) with a high population density (357 people $/ \mathrm{km}^{2}$ ). Therefore the relatively high overall $\mathrm{PM}_{10}$ background pollution with little spatial variation and with few areas of low pollution $^{30}$ could explain why estimates of local $\mathrm{PM}_{10}$ had no effect in our analysis. A multicentre study with patients from areas with high and low $\mathrm{PM}_{10}$ levels might resolve this issue.

A higher SES was associated with a lower risk of BOS (though not of mortality), but there was no confounding the association between SES and proximity to traffic.

Our findings are also biologically robust because they are consistent with a large body of data on the adverse effects of air pollutants on the lung and cardiovascular system. ${ }^{11} 132131$ The steep decline in the hazard ratios (figure 2) until about $400 \mathrm{~m}$ and little or no additional risk decline beyond about $600 \mathrm{~m}$ are compatible with the known logarithmic decrease in the concentration of vehicle-emitted pollutants with increasing distance from the road. ${ }^{23}$ Ultrafine particles represent a toxicologically important fraction of vehicle emissions, although they hardly affect the mass concentrations of particulates $\left(\mathrm{PM}_{10}\right.$ or $\mathrm{PM}_{2.5}$ ). Combustion-generated ultrafine particles produced by diesel engines are believed to be, at least partly, responsible for the cardiopulmonary effects of outdoor urban air pollution, possibly through proinflammatory effects. ${ }^{32} 33$

Biological plausibility is supported by our observations in over $700 \mathrm{BAL}$ and plasma samples, which revealed inverse associations between distance from major roads and markers of inflammation in BAL and plasma. Neutrophils in particular are known to be involved in the onset of BOS. ${ }^{34}$ Moreover, the study demonstrated that both airway neutrophilia and systemic CRP are prognostic factors for BOS and BOS-related mortality. ${ }^{20} 35$ The association of CRP with distance from a major road is compatible with the notion that inhaled particulates exert systemic inflammatory effects outside the respiratory tract. ${ }^{11}$

After organ transplantation, the 5 -year survival is $45 \%$ for lung, $72 \%$ for heart or liver and $90 \%$ for kidney transplantation. ${ }^{36}$ It is tempting to attribute the higher failure rate of lung transplantation to air pollution. The observed systemic effect could indicate an adverse effect for traffic-related air pollution in other solid organ transplantations, especially the heart.

The observed HRs found in this study allow the authors to estimate that in the lung transplant population, $25 \%$ of the BOS events and $28 \%$ of the deaths could be attributed to living close to a major road $(171 \mathrm{~m})$. These population-attributable fractions are significant not only in terms of patient suffering but also in terms of healthcare costs. The yearly mean cost after lung transplantation is $€ 46100$ for a stable patient and $€ 79100$ for a patient with BOS. ${ }^{37} 38$

In conclusion, the study found that exposure to traffic-related air pollution independently increased the risk of BOS and mortality in lung transplant patients and was associated with lung and systemic inflammation. The observed impact of trafficrelated air pollution is not insignificant and, if confirmed by other studies, has substantial clinical and public health implications.

Funding GMV is holder of the GSK (Belgium) chair in respiratory pharmacology at the KULeuven, and is supported by the Research Foundation Flanders (FWO): G.0643.08 and G.0723.10 and 'Onderzoeksfonds K.U.Leuven (OT/10/050). RV is a research fellow and BMV, DEVR and LJD are senior research fellows of the FWO. The environmental health research at Hasselt University is supported by the FWO (1.5.158.09.N.00) and Internal UHasselt University grants (Bijzonder Onderzoekdsfonds, BOF).

\section{Competing interests None}

\section{Patient consent Obtained.}

Ethics approval This study was conducted with the approval of the Ethical Review Board of the Leuven University Medical Faculty.

Contributors This paper is the first in studying and demonstrating a relation between (traffic-related) air pollution and chronic rejection and mortality after lung transplantation.

Provenance and peer review Not commissioned; externally peer reviewed.

\section{REFERENCES}

1. Christie JD, Edwards LB, Kucheryavaya AY, et al. The Registry of the Internationa Society for Heart and Lung Transplantation: twenty-seventh official adult lung and heart-lung transplant report-2010. J Heart Lung Transplant 2010;29:1104-18.

2. Estenne M, Kotloff RM. Update in transplantation 2005. Am J Respir Crit Care Med 2006;173:593-8.

3. Blondeau K, Mertens V, Vanaudenaerde BA, et al. Gastro-oesophageal reflux and gastric aspiration in lung transplant patients with or without chronic rejection. Eur Respir J 2008;31:707-13.

4. Vos R, Vanaudenaerde BM, Geudens N, et al. Pseudomonal airway colonisation: risk factor for bronchiolitis obliterans syndrome after lung transplantation? Eur Respir J 2008; 31:1037-45.

5. Botha P, Archer L, Anderson RL, et al. Pseudomonas aeruginosa colonization of the allograft after lung transplantation and the risk of bronchiolitis obliterans syndrome. Transplantation 2008;85:771-4.

6. Glanville AR, Aboyoun CL, Havryk A, et al. Severity of lymphocytic bronchiolitis predicts long-term outcome after lung transplantation. Am J Respir Crit Care Med 2008;177:1033-40.

7. Vos R, Vanaudenaerde BM, Verleden SE, et al. Bronchoalveolar lavage neutrophilia in acute lung allograft rejection and lymphocytic bronchiolitis. J Heart Lung Transplant 2010;29:1259-69.

8. Alfaro-Moreno E, Nawrot TS, Vanaudenaerde BM, et al. Co-cultures of multiple cell types mimic pulmonary cell communication in response to urban PM10. Eur Respir $J$ 2008; 32:1184-94.

9. Holian A, Hamilton RF Jr, Morandi MT, et al. Urban particle-induced apoptosis and phenotype shifts in human alveolar macrophages. Environ Health Perspect 1998; 106:127-32.

10. Brunekreef $\mathbf{B}$, Holgate ST. Air pollution and health. Lancet 2002;360:1233-42.

11. Alfaro-Moreno E, Nawrot TS, Nemmar A, et al. Particulate matter in the environment: pulmonary and cardiovascular effects. Curr Opin Pulm Med 2007;13:98-106.

12. Miller KA, Siscovick DS, Sheppard L, et al. Long-term exposure to air pollution and incidence of cardiovascular events in women. N Engl J Med 2007;356:447-58.

13. McCreanor J, Cullinan P, Nieuwenhuijsen MJ, et al. Respiratory effects of exposure to diesel traffic in persons with asthma. N Engl J Med 2007;357:2348-58.

14. Arbex MA, de Souza Conceicao GM, Cendon SP, et al. Urban air pollution and chronic obstructive pulmonary disease-related emergency department visits. J Epidemiol Community Health 2009;63:777-83.

15. Pope CA III, Dockery DW. Health effects of fine particulate air pollution: lines that connect. J Air Waste Manag Assoc 2006;56:709-42.

16. Vos $\mathbf{R}$, Vanaudenaerde BM, Verleden SE, et al. A randomized placebo-controlled trial of azithromycin to prevent bronchiolitis obliterans syndrome after lung transplantation. Eur Respir J 2011;37:164-72.

17. Nawrot TS, Van HE, Thijs L, et al. Cadmium-related mortality and long-term secular trends in the cadmium body burden of an environmentally exposed population Environ Health Perspect 2008;116:1620-8.

18. Vos R, De Vusser K, Schaevers V, et al. Smoking resumption after lung transplantation: a sobering truth. Eur Respir J 2010;35:1411-13.

19. Estenne M, Maurer JR, Boehler A, et al. Bronchiolitis obliterans syndrome 2001: an update of the diagnostic criteria. $J$ Heart Lung Transplant 2002;21:297-310. 
20. Vos R, Vanaudenaerde BM, De Vleeschauwer SI, et al. Plasma C-reactive protein levels correlate with markers of airway inflammation after lung transplantation: a role for systemic inflammation in bronchiolitis obliterans syndrome? Transplant Proc 2009:41:595-8.

21. Jacobs L, Emmerechts J, Mathieu C, et al. Air pollution related prothrombotic changes in persons with diabetes. Environ Health Perspect 2010;118:191-6.

22. Janssen S, Dumont G, Fierens F, et al. Spatial interpolation of air pollution measurements using CORINE land cover data. Atmos Environ 2008;42:4884-903.

23. Zhu Y, Hinds WC, Kim S, et al. Concentration and size distribution of ultrafine particles near a major highway. J Air Waste Manag Assoc 2002;52:1032-42.

24. Perez L, Kunzli N. From measures of effects to measures of potential impact. Int $J$ Public Health 2009:54:45-8.

25. Jerrett M, Finkelstein MM, Brook JR, et al. A cohort study of traffic-related air pollution and mortality in Toronto, Ontario, Canada. Environ Health Perspect 2009:117:772-7.

26. Kunzli N, Jerrett M, Garcia-Esteban R, et al. Ambient air pollution and the progression of atherosclerosis in adults. PLoS One 2010;5:e9096.

27. Hoffmann B, Moebus S, Dragano N, et al. Chronic residential exposure to particulate matter air pollution and systemic inflammatory markers. Environ Health Perspect 2009:117:1302-8

28. Hoffmann B, Moebus S, Kroger K, et al. Residential exposure to urban air pollution, ankle-brachial index, and peripheral arterial disease. Epidemiology 2009:20:280-8.

29. Hoffmann B, Moebus $S$, Mohlenkamp $S$, et al. Residential exposure to traffic is associated with coronary atherosclerosis. Circulation 2007;116:489-96.

30. Nawrot TS, Torfs R, Fierens F, et al. Stronger associations between daily mortality and fine particulate air pollution in summer than in winter: evidence from a heavily polluted region in western Europe. J Epidemiol Community Health 2007:61:146-9.

31. Mills NL, Tornqvist $\mathrm{H}$, Gonzalez MC, et al. Ischaemic and thrombotic effects of dilute diesel-exhaust inhalation in men with coronary heart disease. $N$ Engl J Med 2007;357:1075-82

32. Knol AB, de Hartog JJ, Boogaard H, et al. Expert elicitation on ultrafine particles: likelihood of health effects and causal pathways. Part Fibre Toxicol 2009;6:19.

33. Delfino RJ, Staimer N, Tjoa T, et al. Association of biomarkers of systemic inflammation with organic components and source tracers in quasi-ultrafine particles. Environ Health Perspect 2010;118:756-62.

34. Vanaudenaerde BM, De Vleeschauwer SI, Vos R, et al. The role of the IL23/IL17 axis in bronchiolitis obliterans syndrome after lung transplantation. Am J Transplant 2008; 8:1911-20.

35. Vos R, Vanaudenaerde BM, De Vleeschauwer SI, et al. Circulating and intrapulmonary C-reactive protein: a predictor of bronchiolitis obliterans syndrome and pulmonary allograft outcome. J Heart Lung Transplant 2009;28:799-807.

36. Sayegh $\mathbf{M H}$, Carpenter CB. Transplantation 50 years later-progress, challenges, and promises. N Engl J Med 2004:351:2761-6.

37. van den Berg JW, van Enckevort PJ, TenVergert EM, et al. Bronchiolitis obliterans syndrome and additional costs of lung transplantation. Chest 2000:118:1648-52.

38. Studer SM, Levy RD, McNeil K, et al. Lung transplant outcomes: a review of survival, graft function, physiology, health-related quality of life and costeffectiveness. Eur Respir J 2004;24:674-85.

\section{SAVE TIME AND KEEP INFORMED}

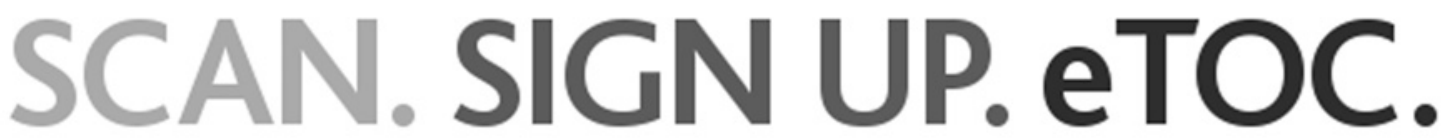

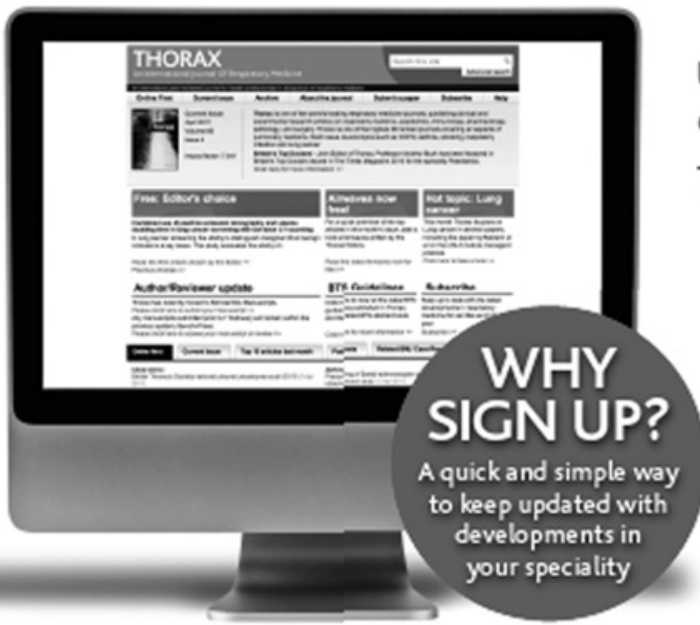

thorax.bmj.com
Utilise our Quick Response code (QR) to sign up for our electronic table of contents (eTOC) alert.

To make this simple you can sign up now via your Smartphone.

\section{FOLLOW THESE}

\section{THREE EASY STEPS:}

1. Downbad a free QR reader from your handset's app store

2. Hold your Smartphone over the QR code

3. You will then be forwarded to the $\mathrm{TOC}$ sign up page

To find out more about $Q R$ codes visit

group.bmjcom/products/journals/qr-codes

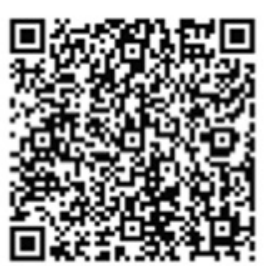

BMJIJournals 